\title{
RAPHANUS SATIVUS LINN. A NEW ANTINOCICEPTIVE FOR DIABETIC NEUROPATHY IN RATS DETERMINED BY RANDALL SELITTO APPROACH
}

\author{
SAMBIT KUMAR SAHO0, STHITAPRAGNYA PANDA* \\ Department of School of Pharmaceutical Sciences, SOA Deemed to be University, Bhubaneswar, Odisha, India. \\ Email: sthitapragnyapanda@soa.ac.in
}

Received: 04 December 2018, Revised and Accepted: 09 January 2019

\section{ABSTRACT}

Objective: The objective of the study was to evaluate the antinociceptive effect of Raphanus sativus Linn. using Randall Selitto method.

Methods: Streptozotocin, lard, casein, cholesterol, DL-methionine, yeast powder, quercetin, thiobarbituric acid, 2-nitrobenzoic acid (5, 5, Dithiobis), hematoxylin, and hydrogen peroxide were used. A diet rich in fat content was fed to the animals for a period of 2 weeks. After a stabilization period of 2 weeks, the treatment period started and continued for a period of 8 weeks. The nociceptive parameters were assessed once a week by Randall Selitto method and hot plate test. After treatment, the animals were sacrificed, and antioxidant parameters were assessed using sciatic nerve homogenate and histopathological analysis of sciatic nerve.

Results: Treatment $R$. sativus extract (RSE $100 \mathrm{mg} / \mathrm{kg}$ and $200 \mathrm{mg} / \mathrm{kg}$ ) appreciably declined the levels of blood glucose in a dose-dependent manner, and it was comparable with standard quercetin. A significant increase in pain threshold levels was observed by the treatment RSE in hot plate method after the $4^{\text {th }}$ week compared to diabetic control, and it was consistent until the end of treatment $(p<0.01, p<0.001)$. In Randall Selitto method RSE produced a significant increase in paw withdrawal threshold after the $4^{\text {th }}$ week compared to diabetic control, and it was consistently increased until the end of treatment. RSE (100 and $200 \mathrm{mg} / \mathrm{kg}$ ) significantly restored the levels of antioxidant enzymes and decreased lipid peroxidation in a dosedependent fashion in comparison with the diabetic control group. RSE (100 mg/kg and $200 \mathrm{mg} / \mathrm{kg})$ attenuated the nerve degeneration and axonal swelling along with quercetin.

Conclusion: The findings from the current study showed the antinociceptive and antioxidant effect of $R$. sativus in neuropathic pain in diabetes.

Keywords: Raphanus sativus Linn., Streptozotocin, Type II diabetes mellitus, Sciatic nerve, Antinociceptive effect, Randall Selitto method.

(C) 2019 The Authors. Published by Innovare Academic Sciences Pvt Ltd. This is an open access article under the CC BY license (http://creativecommons. org/licenses/by/4. 0/) DOI: http://dx.doi.org/10.22159/ajpcr.2019.v12i3.31003

\section{INTRODUCTION}

Plant contemplates as one of the most important sources for developing a synthetic molecule in new drug development and discovery. In ancient histories, traditional remedies of herbal medication were preferred for treating people with acute and chronic illness. Raphanus sativus (RS) Linn. is considered as one of them. It belongs to the family Brassicaceae commonly known as a radish. It is being widely cultivated all over the country, mainly in China and Mediterranean countries for almost 1000 years. The leaves, seeds, and roots of RS Linn. are used as antirheumatic, analgesic, antiarthritic, hepatotropic, antifungal, antioxidative, anti-HIV, antineoplastic, and choleretic [1]. In Churu Rajasthan, this is getting used traditionally for the treatment of rheumatism, diarrhea, asthma, and piles [2]. In various parts of India, the extract of RS Linn. is being used for constipation [3]. It has various chemical constituents such as isothiocyanate, myrosinase, and glucasinolate are produced by this plant. The ethanolic extract showed higher activity and dose-dependent scavenging of free radical than methanolic and water extracts in vitro [4]. RS Linn. proven to have antioxidants, phytotoxins, antibacterial, antiinflammatory, and free radical scavenging properties and its also being used as companion plant because it repels the pest and insect due to its pungent odor [5]. RS Linn. contains Vitamin C, carotenoids, flavonoids, and fibers and also a group of health-promoting metabolites called glucosinolates. Therefore, consumption of Brassicaceae vegetables may prevent the risk of cancer and reduces the inflammation response. This research aimed to investigate and justify the antinociceptive potential of RS Linn. using a high-fat diet (HFD) and Streptozotocin (STZ) (low dose)induced diabetic neuropathy in rats [6]. Type 2 diabetes is a progressive disease characterized by hyperglycemia with insulin resistance in early condition [7]. Nerve damage gets developed all around the body of a patient suffering from type 2 diabetes mellitus (DM) over a long period of time. Neuropathies can be peripheral, focal, and proximal in type. Associated with varying symptoms like numbness, tingling sensation, pain in feet's, toes and arms and muscular wasting which causes ample discomfort to a patient [8-11] The often chosen pathway for chemical induction of type 2 diabetes in rats is through STZ. The long-term elevated glucose level in the blood is easy to cause a variety of diabetic complication such as neuropathy, nephropathy, cardiopathy, and retinopathy [12]. Due to its cytotoxic action on pancreatic $\beta$ - cell, hyperglycemia is manifested. Due to its reproducibility; STZ is the first line choice for inducing diabetes chemically $[13,14]$.

METHODS

\section{Plant material}

The fresh leaves of R S Linn. collected from local markets of interior villages of Bhubaneswar, Odisha during August 2018. Identified and authenticated by Professor Dr. D.P Ray of Regional Plant Resource Centre Bhubaneswar, Odisha, bearing accession number (PN/01). The collected leaves were shade dried and converted to powder with the help of mixer grinder. The collected powder was accurately weighed and kept in a well-closed airtight container [1,15].

\section{Animals}

Healthy, male adult Wistar rats (150-250 g) were issued from SOA Deemed to be University animal house, Bhubaneswar, Odisha. The animals were kept under the appropriate condition as mentioned in CPCSEA guidelines. The animals were maintained with palate diet and potable drinking water, provided by the institution. Experimentation was conducted after obtaining prior approval of IAEC (Approval no. 
SOA/SPS/IAEC/2018/07) under the School of Pharmaceutical Sciences, SOA Deemed to be University, Bhubaneswar, Odisha.

\section{Chemicals}

The chemicals STZ, metformin, and quercetin, were obtained from S D Fine-chemicals Mumbai, India. All other chemicals, solvents, and reagents used were obtained from the Department of Pharmacology from the School of Pharmaceutical Sciences, Siksha O Anusandhan (Deemed to be University), Bhubaneswar, Odisha.

\section{Preparation of extract}

Step involved in the extraction of crude drugs

- Suitable size reduction of dried plant material.

- Extraction by the process of continuous hot percolation or Soxhlet apparatus using $70 \%$ ethanol.

- Removal of the solvent to obtain the extract.

Process

The shade dried leaves were further dried at $25^{\circ} \mathrm{C}$ for 3 days. These dried leaves were exposed to grinding and given to a form of coarse powder. These powders were transferred and extracted using $70 \%$ ethanol for 1 day. The extract obtained was dried in a water bath at $70^{\circ} \mathrm{C}$. The product obtained was stored in desiccators. The extracted yield percentage was calculated as mentioned below.

$\%$ yield $=$ weight of extract $/$ weight of powder $\times 100$

$=86 / 270 \times 100$

$=31.8 \%$

The required amount of extract was dissolved in sterile water and used for in vivo pharmacological studies.

Development of type 2 DM in rats using STZ and HFD [16-18]

For a period of 2 weeks, the HFD was administered to the animals. The constituents of the fat diet were given below. After completion of the above said time, the induction of diabetes was done by intraperitoneal injection of STZ (35 mg/kg body weight). The blood glucose levels were further monitored with the help of one touched glucometer. Those animals exhibiting the level of blood glucose $>300 \mathrm{mg} / \mathrm{dl}$ were considered for further pharmacological analysis.

\section{The composition of a HFD}

\begin{tabular}{lll}
\hline S. No. & Constituents & Diet $\mathbf{g} / \mathbf{k g}$ \\
\hline 1 & NPD (Powder) & 365 \\
2 & Lard & 310 \\
3 & Casein & 250 \\
4 & Cholesterol & 10 \\
5 & DL-methionine & 03 \\
6 & Powdered yeast & 01 \\
7 & NaCl & 01 \\
\hline
\end{tabular}

\section{Treatment schedule}

The basal recording of nociception reaction was noted and the animals were grouped in the following manner and exposed to further treatment for 8 weeks.

- Group I - Normal control

- Group II - Diabetic control

- Group III - Diabetic + RS extract (RSE) $(100 \mathrm{mg} / \mathrm{kg})$

- Group IV - Diabetic + RSE $(200 \mathrm{mg} / \mathrm{kg})$

- Group V - Diabetic + Quercetin (100 mg/kg)

The parameters measured during the drug treatment are blood glucose levels (single and multiple dose study); antinociceptive parameters (hot plate method and Randall Selitto method) were measured once in a week for 8 weeks. After 8 weeks, the treated animals were euthanized and sacrificed, and the sciatic nerve was removed to assess antioxidant parameters.

\section{Experimental design}

Measurement of blood glucose level [19]

The rats were administered with a single dose of respective test and standard drugs; the plasma glucose level was measured before drug administration at 1, 2, and $4 \mathrm{~h}$. In a multiple-dose study for a duration of 11 days, the animals were treated with the same dose and monitoring the level of blood glucose was done on $3^{\text {rd }}, 5^{\text {th }}, 7^{\text {th }}, 9^{\text {th }}$, and $11^{\text {th }}$ days.

\section{Measurement of antinociceptive activity}

The antinociceptive activity was assessed every week during the treatment period, and it was carried out for 8 weeks. The antinociceptive activity was measured using the following methods.

\section{Hot plate method [20]}

The hot plate was stabilized at $52^{\circ} \mathrm{C} \pm 0.5^{\circ} \mathrm{C}$. The individual animal was placed on the surface of the hot plate for a time period until response such as paw licking or jumping has appeared. $20 \mathrm{~s}$ cutoff time was maintained to abstain from any injury to rat paw. This method served as an index of pain threshold.

\section{Randall Selitto mechanical hyperalgesia test [11,21]}

This method was used for measuring antinociceptive activity it was carried out by applying pressure on hind paw and measuring the threshold of foot withdrawal using Ugo Basile Analgesy-meter. The dorsal surface of the rat

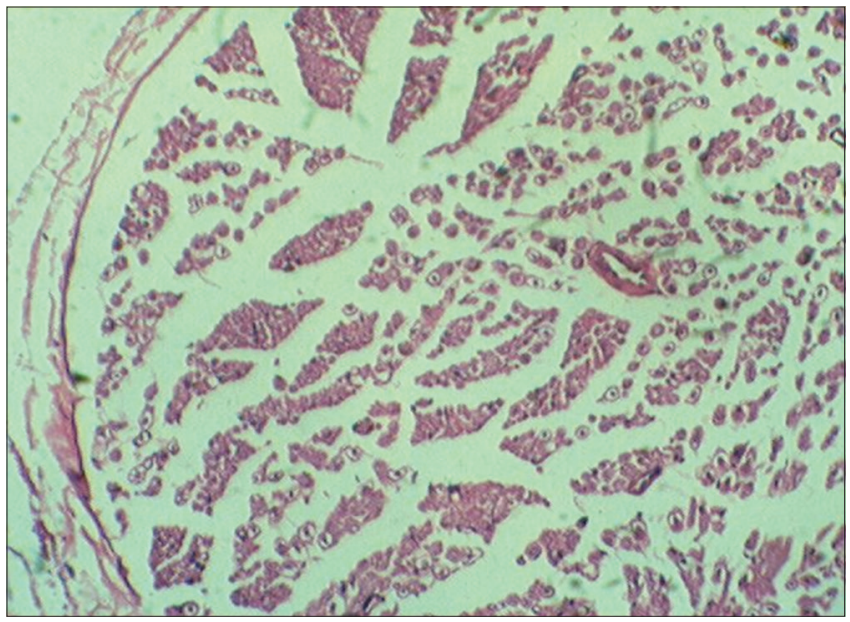

Fig. 1: Control

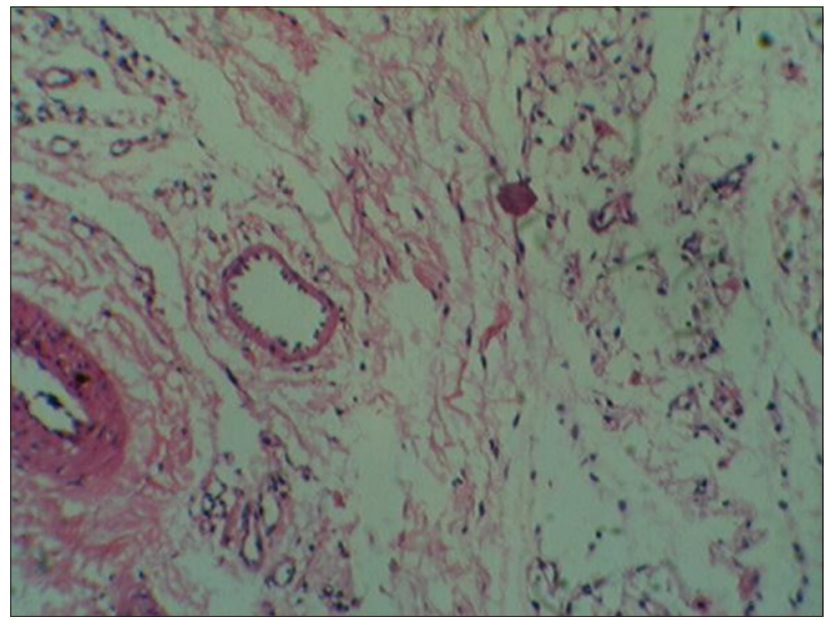

Fig. 2: Diabetic control 


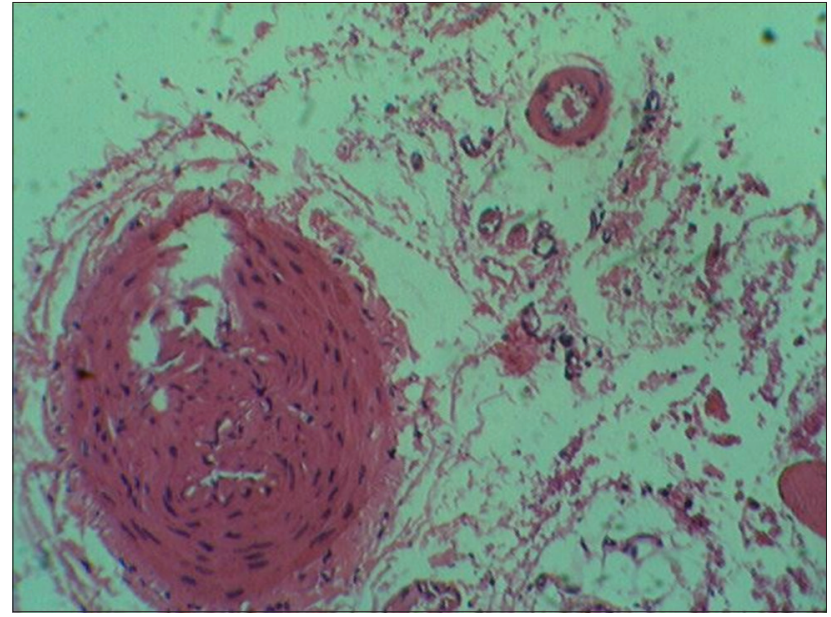

Fig. 3: Quercetin $(100 \mathrm{mg} / \mathrm{kg})$

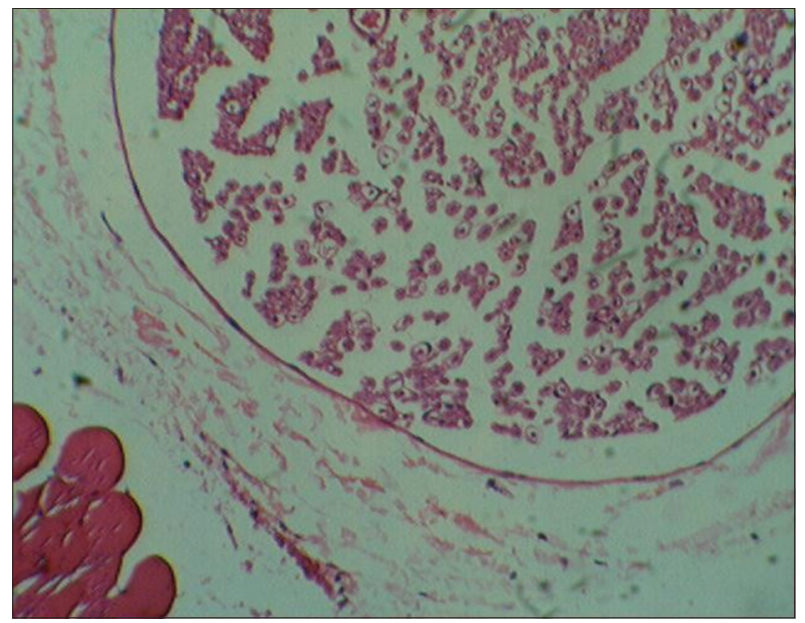

Fig. 4: Raphanus sativus extract $(100 \mathrm{mg} / \mathrm{kg})$

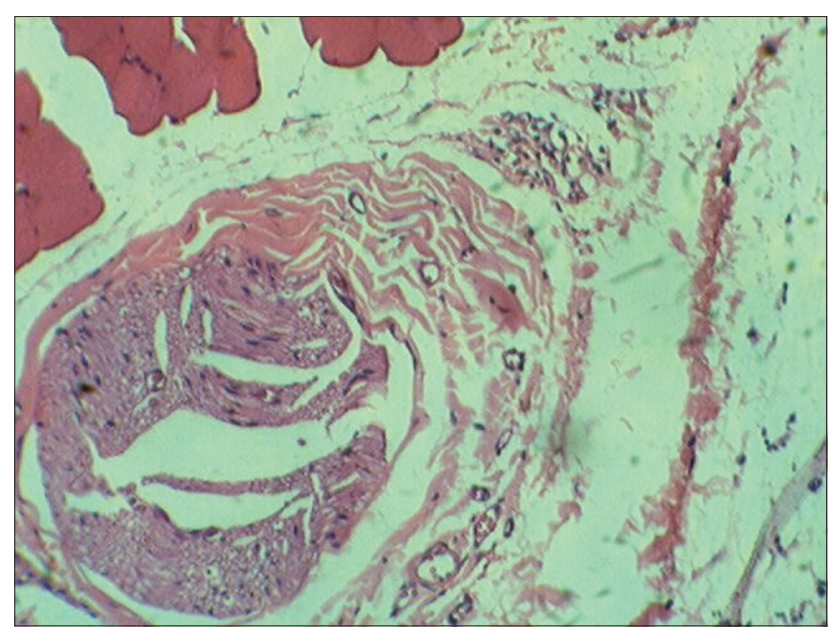

Fig. 5: Raphanus sativus extract $(200 \mathrm{mg} / \mathrm{kg})$

paw was kept under the domed shaped plastic tip. The instrument linearly increases the mechanical force on the rat paw with the help of the tip and this force was applied until the withdrawal of paw was seen.

\section{Antioxidant parameters}

After the treatment period for 8 weeks, rats were killed by cervical dislocation, sciatic nerve carefully exposed, and dissected. The sciatic nerve was homogenized with $1 \mathrm{ml}$ ice-cold sodium phosphate $0.1 \mathrm{~mol} / \mathrm{l}$ buffer having $\mathrm{pH}$ 6.5. The obtained homogenates were subjected to centrifugation at $20,000 \mathrm{rpm}$, and the obtained supernatant was subjected for further assays of activity of the following enzymes.

\section{Estimation of malondialdehyde (lipid peroxidation) [22]}

Tris buffer $0.5 \mathrm{ml}$ and $0.5 \mathrm{ml}$ of supernatant fraction was subjected to incubation for $2 \mathrm{~h}$ at $37^{\circ} \mathrm{C}$. After the addition of trichloroacetic acid ( $01 \mathrm{ml})$, centrifugation was done for $10 \mathrm{~min}$ at $1000 \mathrm{rpm}$. To $1 \mathrm{ml}$ of supernatant fraction $0.67 \%$, thiobarbituric acid was added. For about $10 \mathrm{~min}$, the tubes were kept in boiling water, and then the tubes were allowed to cool followed by which $1 \mathrm{ml}$ of distilled water addition was done, and its absorbance got measured at $532 \mathrm{~nm}$. Quantification of thiobarbituric acid derivatives was done using extinction coefficient and got expressed as $\mathrm{n}$ mole of malondialdehyde per mg protein $1.56 \times 10^{5} \mathrm{M}^{-1} \mathrm{~cm}^{-1}$

\section{Estimation of glutathione (reduced) (GSH) [19]}

Precipitation of $1 \mathrm{ml}$ of the supernatant was done with $1 \mathrm{~mL}$ of trichloroacetic acid $(10 \%)$. For $1 \mathrm{~h}$, the sample was maintained at $4^{\circ} \mathrm{C}$ and further centrifuged at $1200 \mathrm{rpm}$ for a duration of $15 \mathrm{~min}$ at $4^{\circ} \mathrm{C}$. The assay mixture contained $2.7 \mathrm{ml}$ phosphate buffer ( $0.1 \mathrm{M}, \mathrm{pH} 7.4), 0.2 \mathrm{ml} \mathrm{5}$, 5, dithiobis (2-nitrobenzoic acid) (Ellman's reagent, and $0.1 \mathrm{mM}, \mathrm{pH} 8.0$ ) was given to total volume of $3.0 \mathrm{ml}$. The absorbance got measured at $412 \mathrm{~nm}$, and the concentration of GSH was expressed as $\mu \mathrm{g} / \mathrm{mg}$.

\section{Estimation of superoxide dismutase (SOD) [23]}

The activity of SOD got measured using hematoxylin auto-oxidation method. The assay mixture contained phosphate buffer $(50 \mathrm{~mm})$, $0.1 \mathrm{~mm}$ EDTA. $2 \mathrm{ml}$ of this mixture was placed in a cuvette and $0.05 \mathrm{ml}$ of supernatant, hematoxylin got added to it hematoxylin auto-oxidation inhibition was measured at $560 \mathrm{~nm}$ using UV-visible spectrophotometry. Enzymatic activity was expressed as $\mathrm{U} / \mathrm{mg}$ of protein.

\section{Estimation of catalase [24]}

Assay mixture consisted of phosphate buffer ( $50 \mathrm{mmol} / 1 \mathrm{ml}$ ), $0.9 \mathrm{ml}$ of hydrogen peroxide and $0.1 \mathrm{ml}$ of supernatant fraction (10\%) were given to the final volume of $3 \mathrm{ml}$. The absorbance got measured at $240 \mathrm{~nm}$. Enzymatic activity was calculated by molar extinction coefficient $2.04 \mathrm{mmol} / \mathrm{l}$, and enzyme activity was expressed as $\mathrm{U} / \mathrm{mg}$ protein.

\section{Histopathological studies [17]}

The dissected sciatic nerve was preserved in formalin $(10 \%)$ and sliced into $4 \mu \mathrm{m}$ thickness. Hematoxylin and eosin were used for staining. T.S of nerve was qualitatively analyzed under high-resolution research binocular microscope $(\times 100)$ for fiber derangement, axonal degeneration, and axonal swelling.

\section{Statistical analysis}

The results were expressed in the form of mean \pm standard deviation (SD), and statistics for biochemical parameters were done using ANOVA (one-way) followed by Turkey's multiple comparison tests. Behavioral parameters were expressed using ANOVA (two way) used followed by Bonferroni post-test, using GraphPad Prism version 5 software.

\section{RESULTS}

The activity of RS Linn. on levels of blood glucose (single and multiple dose analysis)

STZ-treated animals reflected marked elevation in the level of blood sugar in comparison to normal control rats $(\mathrm{p}<0.001)$. Treatment with RSE $(100 \mathrm{mg} / \mathrm{kg}$ and $200 \mathrm{mg} / \mathrm{kg}$ ) elicited steep fall in levels of blood glucose after $2 \mathrm{~h}$. RSE $(100 \mathrm{mg} / \mathrm{kg})$ reflected $11.67 \%$ reduction in levels of blood glucose after $4 \mathrm{~h}$ whereas RSE (200 mg/kg) showed $14.52 \%$ reduction and a thereafter slight increase in blood levels was observed in comparison to standard drug. The changes in blood glucose levels were given in Table 1. 
Table 1: Effect of RSE on levels of blood glucose (single dose study)

\begin{tabular}{|c|c|c|c|c|c|}
\hline \multirow[t]{2}{*}{ S. No. } & \multirow[t]{2}{*}{ Treatment } & \multicolumn{4}{|c|}{ Level of blood glucose (mg/dl) } \\
\hline & & $\mathbf{O} \mathbf{h}$ & $1 \mathrm{~h}$ & $2 \mathrm{~h}$ & $4 \mathrm{~h}$ \\
\hline 1 & Normal control & $89.33 \pm 9.498$ & $89.16 \pm 7.543$ & $89.83 \pm 6.432$ & $89.16 \pm 8.957$ \\
\hline 3 & Diabetic+quercetin $(100 \mathrm{mg} / \mathrm{kg})$ & $317.11 \pm 26.764$ & $316.23 \pm 24.874$ & $280.33 \pm 20.509 * *$ & $271.5 \pm 18.234^{* * *}$ \\
\hline 4 & Diabetic+RSE (100 mg/kg) & $327.02 \pm 23.952$ & $324.53 \pm 19.875$ & $297.16 \pm 18.897 *$ & $289.66 \pm 22.567 * *$ \\
\hline 5 & Diabetic+RSE (200 mg/kg) & $323.33 \pm 23.451$ & $322.51 \pm 21.924$ & $281.49 \pm 20.675^{* *}$ & $276.05 \pm 19.243^{* * *}$ \\
\hline
\end{tabular}

All value is expressed as mean $\pm \mathrm{SD}(\mathrm{n}=6) .{ }^{* * *} \mathrm{p}<0.001,{ }^{* *} \mathrm{p}<0.01,{ }^{*} \mathrm{p}<0.05$ in comparison to the diabetic control. \#\#\# $\mathrm{p}<0.001$ as compared to normal control. (Two-way)

ANOVA followed by Bonferroni multiple comparison tests. SD: Standard deviation, RSE: Raphanus sativus extract

Table 2: Effect of RSE on levels of blood glucose (multiple dose study)

\begin{tabular}{|c|c|c|c|c|c|c|}
\hline \multirow[t]{2}{*}{ S. No. } & \multirow[t]{2}{*}{ Treatment } & \multicolumn{5}{|c|}{ Level of blood glucose (mg/dl) } \\
\hline & & $3^{\text {rd }}$ day & $5^{\text {th }}$ day & $7^{\text {th }}$ day & $9^{\text {th }}$ day & $11^{\text {th }}$ day \\
\hline 1 & Normal control & $84.66 \pm 7.952$ & $86.16 \pm 5.672$ & $87.33 \pm 8.345$ & $85.59 \pm 7.925$ & $85.83 \pm 9.172$ \\
\hline 3 & Diabetic+Quercetin $(100 \mathrm{mg} / \mathrm{kg})$ & $271.33 \pm 19.232^{* *}$ & $255.38 \pm 20.632^{* * *}$ & $231.78 \pm 15.824^{* * *}$ & $211.03 \pm 15.723^{* * *}$ & $192.83 \pm 13.943^{* * *}$ \\
\hline 4 & Diabetic+RSE $(100 \mathrm{mg} / \mathrm{kg})$ & $288.16 \pm 23.538^{*}$ & $273.02 \pm 20.636^{* * *}$ & $260.51 \pm 18.763^{* * *}$ & $239.33 \pm 16.935^{* * *}$ & $218.82 \pm 13.945^{* * *}$ \\
\hline 5 & Diabetic+RSE (200 mg/kg) & $275.66 \pm 24.874^{* *}$ & $263.59 \pm 22.873^{* * *}$ & $250.51 \pm 19.753^{* * *}$ & $227.16 \pm 20.543^{* * *}$ & $210.54 \pm 14.534^{* * *}$ \\
\hline
\end{tabular}

All value is expressed as mean $\pm \operatorname{SD}(\mathrm{n}=6) .{ }^{* * *} \mathrm{p}<0.001,{ }^{* *} \mathrm{p}<0.01,{ }^{*} \mathrm{p}<0.05$ in comparison to diabetic control. \#\#\# $\mathrm{p}<0.001$ as compared to normal control. (Two-way)

ANOVA followed by Bonferroni multiple comparison tests. SD: Standard deviation, RSE: Raphanus sativus extract

In a multiple-dose study, administration of RSE showed a steep decrease in the level of blood glucose from day 3 in a dose-dependent manner. RSE $(200 \mathrm{mg} / \mathrm{kg})$ showed the highest decline in the level of blood glucose between day 9 and day 11 and percentage reduction was found to be 17.46-23.64. The changes in blood glucose levels were given in Table 2.

\section{Effect of RSE on nociceptive parameters \\ Hot plate method}

The threshold of nociception was very low in diabetes-induced rats when compared to basal value tested animals. Hyperalgesia diabetic was observed after the $1^{\text {st }}$ week of treatment $(\mathrm{p}<0.05)$ and $2^{\text {nd }}$ week $(\mathrm{p}<0.01)$ and steep reduction in pain threshold was seen after the $3^{\text {rd }}$ week in comparison to control animals $(\mathrm{p}<0.001)$ and was maintained until the termination of the treatment period. Administration of quercetin and RSE $200 \mathrm{mg} / \mathrm{kg}$ which increases pain threshold in diabetic group in comparison to control animals after the $3^{\text {rd }}$ week $(\mathrm{p}<0.01, \mathrm{p}<0.05)$ and RSE $100 \mathrm{mg} / \mathrm{kg}$ produced significant effect after the $4^{\text {th }}$ week $(p<0.01)$. The highest increase in pain threshold was seen after the $4^{\text {th }}$ week $(p<0.001)$ for both RSE $(200 \mathrm{mg} / \mathrm{kg})$ and quercetin and it was maintained until the end of the treatment period. The changes in the pain threshold levels were given in Table 3.

\section{Mechanical hyperalgesia test (Randall Selitto method)}

The paw withdrawal threshold was reduced to a much greater extent as compared to the basal value recorded. Mechanical hyperalgesia was evident in diabetic rats after the $2^{\text {nd }}$ week of treatment $(\mathrm{p}<0.05)$ and a steep decrease in paw withdrawal threshold was seen after the $3^{\text {rd }}$ week in comparison with normal control rats $(\mathrm{p}<0.001)$ and was maintained until the termination of the treatment period. Administration of RSE $200 \mathrm{mg} / \mathrm{kg}$ and quercetin to diabetic group elicited a rise in withdrawal threshold in a dose-dependent manner in comparison to control animals after the $4^{\text {th }}$ week $(\mathrm{p}<0.01, \mathrm{p}<0.001)$. Maximum rise in the withdrawal threshold was observed after the $5^{\text {th }}$ week $(\mathrm{p}<0.001)$ for RSE $100 \mathrm{mg} / \mathrm{kg}$ and $200 \mathrm{mg} / \mathrm{kg}$ and quercetin and it was kept until the treatment tenure was over. The changes in the withdrawal threshold were given in Table 4.

Effect of RSE on antioxidant parameters using sciatic nerve homogenate

Levels of the sciatic nerve (MDA) were remarkably very high in diabetic group in comparison to the normal control group $(p<0.001)$. Treatment using RSE $(100 \mathrm{mg} / \mathrm{kg}$ and $200 \mathrm{mg} / \mathrm{kg})$ and quercetin for a period of 8 weeks significantly lowered the MDA levels in dose-dependent fashion $(\mathrm{p}<0.001, \mathrm{p}<0.01)$.

Significantly lower levels of antioxidant enzymes peroxidase and dismutase were seen in diabetic rats in comparison with normal control rats $(\mathrm{p}<0.001)$. Treatment with RSE $(100 \mathrm{mg} / \mathrm{kg}$ and $200 \mathrm{mg} / \mathrm{kg})$ and quercetin remarkably increases the levels of catalase, SOD and GSH $(p<0.001, p<0.01)$ and thereby restoring the levels to normal. The effect of RSE was found to be in a dose-dependent fashion. Changes in the levels of lipid peroxidation and antioxidant enzymes are given in Table 5 .

\section{Histopathological analysis}

\begin{tabular}{|c|c|c|}
\hline S.No. & Group & Result \\
\hline 1 & Control & $\begin{array}{l}\text { A normal architecture nerve fiber is seen } \\
\text { with no degenerative fibers }\end{array}$ \\
\hline 2 & Diabetic control & $\begin{array}{l}\text { Extensive derangement of nerve fibers, } \\
\text { axonal degeneration, and swelling }\end{array}$ \\
\hline 3 & $\begin{array}{l}\text { Quercetin } \\
(100 \mathrm{mg} / \mathrm{kg}) \\
\text { treated group }\end{array}$ & $\begin{array}{l}\text { Moderate fiber derangement with axonal } \\
\text { degeneration }\end{array}$ \\
\hline 4 & $\begin{array}{l}\text { RSE } \\
\text { (100 mg/kg) } \\
\text { treated a group }\end{array}$ & $\begin{array}{l}\text { Extensive derangement of nerve fiber } \\
\text { with moderate axonal degeneration }\end{array}$ \\
\hline 5 & $\begin{array}{l}\text { RSE } \\
\text { (200 mg/kg) } \\
\text { treated a group }\end{array}$ & $\begin{array}{l}\text { Fiber derangement with moderate } \\
\text { axonal degeneration }\end{array}$ \\
\hline
\end{tabular}

Photomicrographs of sciatic nerve

\section{DISCUSSION}

Randal Selitto method has not been used for establishing the antinociceptive potential of RS. This plant has widespread cultivation in anterior villages of Bhubaneswar, Odisha, so this would serve as a suitable and economic alternative for neuropathic complications associated with diabetic patients. DM is a metabolic complication comprising several pathological changes such as hyperglycemia, insulin resistance, glucose tolerance, and hypertriglyceridemia. Oxidative stress gets induced due to hyperglycemia and results in activation of 

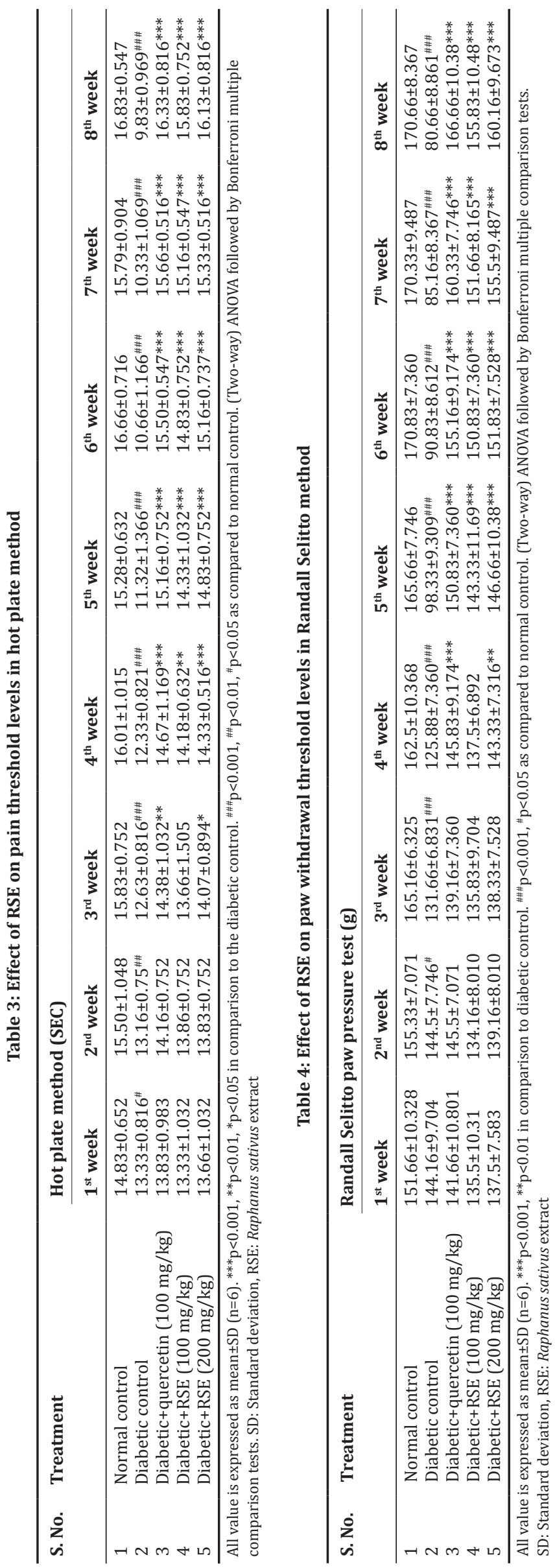

various biochemical pathways and further leads to advanced glycation end products formation on extracellular and intracellular circulating proteins which plays a key role in the mediation of secondary diabetic complications. The rise in oxidative stress leads to impairment of vasculature due to endoneurial hypoxia which results in abnormal neuronal activity, poor neurotrophic support, and reduction in conduction velocity. Oxidative stress in diabetes rats causes the generation of free radicals that cause endothelial damage to the sciatic nerve. The dietary antioxidants improve vascular resistance on diabetic rats by scavenging reactive oxygen species. Whereas it is unlimited and easy, access to bodily metabolic, a process in case of natural antioxidants and do not possess any sort of side effects. In the current study, RSE showed a marked decrease in blood glucose level in the single and multiple dose study, which was consistent with reports earlier. DM-induced in rats was done with the help of single dose STZ injection and modified diet, which showed a diabetic state that was similar to type 2 DM in human. Hence, a diet with high-fat content and STZ low dose were used to induce type 2 DM in this study. The most common complication of diabetic neuropathy is neuropathic pain, which was the main target of the research we observed a steep decrease in pain threshold in diabetes-induced rats when compared with normal control, which indicates thermal hyperalgesia. Moreover, flavonoids like rutin have found to be potent analgesic and antidiabetic; quercetin has already been incorporated in clinical trials for diabetic neuropathy. The presence of these flavonoids may be responsible for attenuating diabetic neuropathy pain. Further, it is also reported that there is a (chemical) structural similarity between flavonoids and cannabinoids; hence, they may have direct interaction with the cannabinoid receptors. Cannabinoids have shown a reduction in pain sensation by acting through brain stem circuits, which leads to pain suppressing mechanism as like of opiates. Treatment with quercetin and RSE significantly increase pain threshold in comparison with diabetic rats induced group. In the present study, the diabetic group exhibited remarkable mechanical hyperalgesia in comparison to normal control group, which was consistent in earlier reports that state, when diabetes is induced by STZ within a period of 1-8 weeks there is the development of mechanical hyperalgesia. Treatment with RSE and quercetin significantly restored the paw withdrawal threshold. The actual mechanism, which is held responsible for the decrease in the level of pain threshold, has not been completely established. Mechanisms that are postulated in leading to neuropathic pain in diabetes are mainly COX activation, oxidative stress, opioidergic, and voltage-gated sodium channel. Treatment with RSE increases the pain threshold and paw withdrawal pressure, which suggested the role of oxidative stress in neuropathic pain associated with diabetes.

\section{CONCLUSION}

This study is attempted to investigate the antinociceptive activity of RS Linn. using a diet containing high fat and using a lower dosage of STZ for inducing diabetic neuropathy in Wistar rats. Randal Selitto a new approach for measuring neuropathic pain was used in this research. For a period of 14 days, the animals were maintained with diet having a high content of fat and then treated with STZ $35 \mathrm{mg} / \mathrm{kg}$ to overnight fasted rats. The animals were treated for 8 weeks, respectively. The levels of blood glucose were further monitored. It was found that steep decrease in the level of blood glucose in RSE $100 \mathrm{mg} / \mathrm{kg}$ and $200 \mathrm{mg} / \mathrm{kg}$ in a dose-dependent manner, which can be compared with that of the standard drug in both single and multiple dose studies. The nociceptive parameters were measured once a week during the treatment period of 8 weeks. In the hot plate method, it was found that there is a significant rise in levels of pain threshold in the RSE in a dose-dependent manner and quercetin-treated group when compared to diabetic control. In Randall Selitto method, the threshold of paw withdrawal was markedly decreased in the diabetic group, which was restored by treatment of RSE $100 \mathrm{mg} / \mathrm{kg}$ and $200 \mathrm{mg} / \mathrm{kg}$ in a dose-dependent way as in comparison to the standard drug. In vivo oxidative stress was assessed by estimating biochemical parameters such as lipid peroxidation, superoxide dismutase, GSH, and catalase from the homogenate of the sciatic nerve. 
Table 5: Effect of RSE on in vivo antioxidant parameter using sciatic nerve homogenate

\begin{tabular}{llllll}
\hline \multirow{2}{*}{ S. No. } & \multirow{2}{*}{ Treatment } & \multicolumn{2}{l}{ Antioxidant parameters } \\
\cline { 3 - 6 } & & $\begin{array}{l}\text { Lipid peroxidation } \\
(\mu \mathrm{G} / \text { MG protein) }\end{array}$ & $\begin{array}{l}\text { Superoxide dismutase } \\
\text { (U/MG protein) }\end{array}$ & $\begin{array}{l}\text { Reduced glutathione } \\
\text { (U/MG protein) }\end{array}$ & $\begin{array}{l}\text { Catalase } \\
\text { (U/MG protein) }\end{array}$ \\
\hline 1 & Normal control & $1.53 \pm 0.091$ & $34.1 \pm 4.05$ & $78.3 \pm 5.89$ & $0.31 \pm 0.04$ \\
2 & Diabetic control & $4.73 \pm 0.128^{\# \# \#}$ & $8.02 \pm 3.35^{\# \# \#}$ & $37.8 \pm 3.49^{\# \# \#}$ & $0.15 \pm 0.0379^{\# \# \#}$ \\
3 & Diabetic+quercetin $(100 \mathrm{mg} / \mathrm{kg})$ & $2.07 \pm 0.120^{* * *}$ & $29.2 \pm 4.58^{* * *}$ & $67.2 \pm 6.05^{* * *}$ & $0.282 \pm 0.028^{* * *}$ \\
4 & Diabetic+RSE $(100 \mathrm{mg} / \mathrm{kg})$ & $3.92 \pm 0.138^{* *}$ & $18.8 \pm 3.97^{* *}$ & $50.7 \pm 3.67^{* *}$ & $0.253 \pm 0.047^{* *}$ \\
5 & Diabetic+RSE $(200 \mathrm{mg} / \mathrm{kg})$ & $2.60 \pm 0.153^{* * *}$ & $26.7 \pm 4.82^{* * *}$ & $61.1 \pm 4.98^{* * *}$ & $0.267 \pm 0.0455^{* * *}$ \\
\hline
\end{tabular}

All value is expressed as mean $\pm \operatorname{SD}(n=6) .{ }^{* * *} \mathrm{p}<0.001,{ }^{* *} \mathrm{p}<0.01$ in comparison to the diabetic control. \#\#\# $<<0.001$ as compared to normal control. ANOVA (One-way) followed by Turkey's multiple comparison tests. SD: Standard deviation, RSE: Raphanus sativus extract

Treatment with RSE $100 \mathrm{mg} / \mathrm{kg}$ and $200 \mathrm{mg} / \mathrm{kg}$ for 8 weeks attenuated oxidative stress in diabetic rats, in a dose-dependent fashion. The histopathological analysis showed attenuation of axonal degeneration and axonal swelling in both RSE $200 \mathrm{mg} / \mathrm{kg}$ and quercetin-treated groups, which can be compared with that of control and RSE $100 \mathrm{mg} / \mathrm{kg}$ showed moderate axonal degeneration and axonal swelling. It can be concluded that chronic treatment with an ethanolic extract of RS Linn. ameliorated the neuropathic pain and oxidative stress along with the improvement in blood glucose levels in diabetic rats. The mechanisms leading to attenuation of neuropathic pain by RS Linn. may be due to anti-hyperglycemic and antioxidant potential.

Thus, RS Linn. will serve as a salutary and therapeutic alternative for the control and management of neuropathic pain, commonly linked with the patients of DM. Moreover, the research outcome elucidates that Randall sellito approach would serve as a better alternative for analysis and measurement of neuropathic pain in diabetic rats.

\section{ACKNOWLEDGMENT}

This study was supported by the School of Pharmaceutical Sciences, Siksha 0 Anusandhan (Deemed to be University), Bhubaneswar, Odisha. This research did not receive any specific grant from funding agencies in the public, commercial, or not for profit sectors.

\section{AUTHORS' CONTRIBUTIONS}

Sambit Kumar Sahoo (CS, SD, DC, DA, MP, RM, AM), Sthitapragnya Panda (CS, SD, DC, DA, MP), CS - conducting the study; SD - Study design; DC - Data collection; DA - Data analysis; MP - Manuscript preparation; RM - Review of the manuscript; and AM - Approval of the final manuscript.

\section{CONFLICTS OF INTEREST}

The authors declare that they have no competing interest.

\section{REFERENCES}

1. Gutiérrez RM, Perez RL. Raphanus sativus (Radish): Their chemistry and biology. ScientificWorldJournal 2004;4:811-37.

2. Upadhyay PB, Roy S, Kumar A. Traditional uses of medicinal plants among the rural communities of Churu district in the Thar Desert, India. J Ethnopharm 2007;113:387-99.

3. Gilani AH, Ghayur MN. Pharmacological basis for the gut stimulatory activity of Raphanus sativus leaves. J Ethnopharm 2004;95:169-72.

4. Anjaneyulu M, Chopra K. Quercetin, a bioflavonoid, attenuates thermal hyperalgesia in a mouse model of diabetic neuropathic pain. Prog Neuropsychopharmacol Biol Psychiatry 2003;27:1001-5.

5. Beevi SS, Lakshmi NM, Gowda BB. Polyphenolics profile, antioxidant and radical scavenging activity of leaves and stem of Raphanus sativus Linn. Plant Foods Hum Nutr 2010;65:8-17.

6. Asna U, Vanitha RP, Shruthi D, Faiyaz A. Antioxidant properties and stability of Raphanus sativus extracts. J Pharm Res 2010;3:658-61.
7. Hidayati S, Sulistyawati R, Nurani LH. Regulation of ethyl acetate fraction from Moringa oleifera leaves to improve lipid metabolism and insulin sensitivity in type 2 diabetes. Int J Pharm Pharm Sci 2018;10:78-82.

8. Edwards JL, Vincent AM, Cheng HT, Feldman EL. Diabetic neuropathy: Mechanisms to management. Pharmacol Ther 2008;120:1-34.

9. Greene DA, Stevens MJ, Feldman EL. Diabetic neuropathy: Scope of the syndrome. Am J Med 1999;107:2S-8S.

10. Vinik AI, Mitchell BD, Maser RE, Freeman R. Diabetic autonomic neuropathy. Diabetes Care 2003;26:1553-79.

11. Barrière DA, Noll C, Roussy G, Lizotte F, Kessai A, Kirby K, et al. Combination of high-fat/high-fructose diet and low-dose streptozotocin to model long-term type-2 diabetes complications. Sci Rep 2018;8:424.

12. Bachhav R, Saudagar R. Effect of ethanolic flower extract of Spathodea campanulata on streptozotocin-induced diabetic neuropathy. Int J Pharm Pharm Sci 2018;10:64-9.

13. Konrad RJ, Mikolaenko I, Tolar JF, Liu K, Kudlow JE. The potential mechanism of the diabetogenic action of streptozotocin inhibition of pancreatic $\beta$-cell O-GlcNAc selective N-acetyl-b-D-glucosaminidase. Biochem J 2001;356:31-41.

14. Lenzen S. The mechanisms of alloxan- and streptozotocin-induced diabetes. Diabetologia 2008;51:216-26.

15. Orient Longmans. Raphanus sativus Linn. Indian Medicinal Plants. $4^{\text {th }}$ ed. Hyderabad: Orient Longman private limited; 2006. p. 407.

16. Srinivasan K, Viswanad B, Asrat L, Kaul CL, Ramarao P. Combination of high-fat diet-fed and low-dose streptozotocin-treated rat: A model for type 2 diabetes and pharmacological screening. Pharmacol Res 2005;52:313-20.

17. Ramdas BP, Sangameswaran B, Popat BM, Shantaram GK. Attenuating effect of seeds of Adenanthera pavonina aqueous extract in neuropathic pain in streptozotocin-induced diabetic rats: An evidence of neuroprotective effects. Brazil J Pharm 2012;22:428-35.

18. Reed MJ, Meszaros K, Entes LJ, Claypool MD, Pinkett JG, Gadbois TM, et al. A new rat model of type 2 diabetes: The fat-fed, streptozotocintreated rat. Metabolism 2000;49:1390-4.

19. Prem KN, Annamalai AR, Thakur RS. Antinociceptive property of Emblica officinalis Gaertn (Amla) in high fat fed/low dose streptozotocin-induced diabetic neuropathy. Indian J Exp Biol 2009; $47: 737-42$

20. Tsagareli MG, Tsiklauri N, Gurtskaia G, Nozadze I, Abzianidze E. The central nucleus of the amygdala is involved in tolerance to the antinociceptive effect of NSAIDs. Health 2010;2:62-6.

21. Miki S, Yoshinaga N, Iwamoto T, Yasuda T, Sato S. Antinociceptive effect of the novel compound OT-7100 in a diabetic neuropathy model. Eur J Pharmacol 2001;430:229-34.

22. Kanwaljit C, Anurag K, Richa S. Lycopene attenuates the diabetesassociated cognitive decline in rats. Life Sci 2008;83:128-34

23. Mukherjee D, Roy SG, Bandyopadhyay A, Chattopadhyay A, Basu A, Mitra E, et al. Melatonin protects against isoproterenol-induced myocardial injury in the rat: Antioxidative mechanisms. J Pineal Res 2010;48:251-62.

24. Stevens MJ, Obrosova I, Xianghui C, Carol VH, Greene DA. Effects of DL-a-lipoic acid on peripheral nerve conduction, blood flow, energy metabolism, and oxidative stress in experimental diabetic neuropathy. Diabetes 2000;49:1006-15. 